\title{
Nos Labirintos da Lei: A Retórica da Reforma Agrária no Estado Democrático de Direito - Brasil 1995/2006 ${ }^{1}$
}

Jeanne SILVA ${ }^{\circ}$

Resumo: Este artigo tem por objetivo apresentar de forma condensada, parte das reflexões de pesquisa da autora. Discute alguns vínculos entre direito e história. Procura evidenciar historicamente como o direito é uma prática argumentativa, como são construídos e pensados os argumentos que permitem uma elite política traçar os rumos para o país criando uma legislação que criminalize a atuação dos diversos movimentos sociais, mais concretamente o MST- Movimento dos Trabalhadores Rurais Sem Terra, transformando o problema "político" da reforma agrária em caso jurídico e de "polícia".

Palavras-chave: Direito; História Política; Reforma Agrária.

Têmis e Clio são musas gregas que compartilham essência próxima. O vínculo entre justiça, história e verdade é um vínculo de nós emaranhados que ainda hoje merecem análises reflexivas. Segundo a mitologia, foi sob o signo da ambivalente deusa Têmis, fonte da equidade, e da rigorosa Diké, senhora das penas imerecidas, que os homens formaram a idéia primordial do justo, convertendo em mito, a divina potestade. Duas distintas progênies se atribuíram a Têmis: dela ter-se-iam gerado as Horas, que, na lição de Hesíodo, velam sobre o trabalho dos homens, como Eunomia, a legalidade segura observada, como Diké, a retribuição necessária, e Irene, a paz: mas também dela teriam nascido as Parcas, tecelãs do passado,

\footnotetext{
- Doutoranda em História - Programa de Pós-graduação em História Universidade Federal de Uberlândia - UFU - 38400-902 - Uberlândia MG - Brasil. E-mail: jeannes@triang.com.br
} 
JEANNE SILVA

do presente e do futuro, porque não se tece a justiça sem o fim do tempo. Portanto, explica-se assim, mitologicamente a coimplicação entre Têmis e Clio, a crença de que é através da efetivação histórica do tempo, que a justiça se realiza através das normas e de instituições objetivas que zelem pela realização da mesma.

As relações estabelecidas entre a ciência histórica e o direito partilham de traços comuns que convém analisarmos para pensarmos, posteriormente, em como o historiador pode se apropriar das fontes jurídicas com objetivos historiográficos, ou seja, como os processos judiciais podem servir de fontes de pesquisas; e mesmo como as discussões historiográficas podem fazer avançar as ciências jurídicas. O projeto de uma reflexão interdisciplinar, que articule História e Direito, significa pensar sobre qual História e qual Direito possibilitarão tal diálogo. Nesse esforço, o Direito ressurge como experiência histórica, em efetivo diálogo com outras práticas sociais e, principalmente, como um fazer humano, que significa optar por determinados valores, interpretar o mundo e interferir em seus destinos. $O$ processo histórico, por sua vez, aparece como centro de gravidade do Direito, não para transformar este em reflexo de outros fazeres, mas para entender sua condição de prática social complexa. Assim sendo, a lei é explicada por nós na condição de realidade material das relações entre os homens, que não está isenta das relações hierárquicas dominantes nem da capacidade de mobilização de diferentes grupos sociais. Daí, elas abrangerem tanto o Direito acumulado como a luta por novos direitos. Se o Poder Judiciário (bem como os demais poderes legislativo e executivo) privilegia(m) os interesses das elites sociais, isso não significa que sua existência esteja eternamente reduzida à farsa: outros direitos têm sido reivindicados, e até conquistados. É nesse sentido que os movimentos sociais, exemplificados pelo MST, lutam contra certos usos das leis, evidenciando que eles não são inimigos da legitimidade, e sim pensadores de uma ampliação de seus alcances. Daí, a ambigüidade da lei não ser indício de carência lógica, e sim uma 
NOS LABIRINTOS DA LEI: A RETÓRICA DA REFORMA AGRÁRIA...

dimensão de sua existência social, de sua possível recuperação pelos que foram (e são) excluídos no processo de dominação.

Em outro trabalho ${ }^{2}$ discutimos quanto tem sido prejudicial um direito cada vez mais identificado com o poder econômico, que se aperfeiçoa nos institutos jurídicos da defesa da propriedade privada se esquecendo, em contrapartida, dos direitos básicos de todos os homens e mulheres: direito à vida, à dignidade, ao trabalho, à moradia, refletindo sobre o jugo imposto pela lei àqueles que são leigos e a desconhecem e o jogo dos agentes que a operacionalizam, fazendo com que o aumento da desigualdade social amplie também um sentimento de injustiça e descrença na capacidade humana de se fazer justiça aos oprimidos.

$\mathrm{Na}$ discussão da retórica da reforma agrária, analisamos como os diversos agentes (dos três poderes) concebem e operacionalizam um certo conceito do que seja reforma agrária. Partimos dos pronunciamentos dos senadores, de discursos dos Presidentes da República (Fernando Henrique Cardoso e Luís Inácio Lula da Silva), num recorte que evidencia a discussão do tema da Reforma Agrária no Brasil, no período de 1995 a 2006.

Tendo como chave de leitura as técnicas retórica, verificamos que a mesma é um dos instrumentos utilizados por esses agentes políticos na busca do convencimento sobre a importância das teses que defendem para o tema da Reforma Agrária. A pesquisa analisa historicamente os embates sociais e as correlações de forças que se fazem presentes nos processos de elaboração das leis, nos conteúdos, na leitura (compreensão interpretações) e aplicação das mesmas. Desse modo, a pesquisa analisa parte da produção legislativa agrária do período, concebendo a construção das leis e sua aplicação como resultado dos embates sociais, demonstrando historicamente, como na prática, o Estado "democrático" de "direito" brasileiro tem agido no tocante à temática, ou seja, como os poderes Executivo, Legislativo e Judiciário, assim confrontados com as instâncias organizadas da sociedade civil - os Movimentos de Luta pela Terra - têm atuado concretamente nos embates em torno da questão. Questionando-nos, em suma, por que, apesar 
JEANNE SILVA

de tantos discursos, promessas, argumentos, nunca se fez de fato reforma agrária neste país?

Partimos da pergunta inicial "Qual (quais) Reforma(s) Agrária(s)?", pergunta que aparentemente pode parecer simples à primeira vista, mas que carrega complexidades insuspeitas nas análises da vida político-brasileira. Do plano das idéias às ações concretas, diferentes tipos de Reforma Agrária foram imaginadas no contexto brasileiro. Em tese, nenhum político (declaramente em seus discursos) foi ou é contra Reforma Agrária, pois tem vínculações à regra do jogo democrático e estão inseridos numa relação midiática e de opinião pública em relação a seus eleitores. Mas é a partir da análise de seus pronunciamentos, no decorrer do tempo, que as diferenças político-ideológicas vão se delineamendo na formação e no desenrolar do jogo político, pontuando diferenças precisas e marcantes não só entre os partidos políticos (de orientações e propostas diferenciadas entre si) mas também entre os próprios políticos, que às vezes, mesmo sendo de um mesmo partido agem de formas contráditórias, ambiguas. Cada grupo conceitua e defende tipos diferentes de Reforma(s) agrária(s). São essas nuances que revelam, de fato, o compromisso de cada político ou grupo partidário e os jogos de interesse postos em prática. É histórica a retórica de reforma agrária para esse país, onde políticos e autoridades diversas vêm pensando e re-pensando projetos e possibilidades de políticas públicas para a questão agrária, que mesmo com o Estatuto da Terra, e posteriormente com a Constituição Federal de 1988 foram re-problematizadas constantemente e ganharam contornos mais acirrados com a abertura política dos anos 80 do século passado e com o crescimento e a pressão dos Movimentos Sociais dos Trabalhadores Rurais Sem Terra. Durante o período de governo do Presidente Fernando Henrique Cardoso diversos projetos se delinearam e ganharam contornos mais definidos, com isso, marcadas diferenças se transpareceram entre as muitas correntes políticas partidárias (ou não) que defendiam propostas diferenciadas para cada tipo de Reforma Agrária. Com o agravamento das questões sociais, a exacerbação dos bolsões 
NOS LABIRINTOS DA LEI: A RETÓRICA DA REFORMA AGRÁRIA...

de pobreza, tanto do campo quanto das cidades, o conflito agrário se recrudesceu com maior visibilidade da violência ocorrida no campo - como exemplo do Massacre de Eldorado dos Carajás no Pará, O massacre de Corumbiara entre tantos outros focos localizados em diversas partes do país, mortes e prisões de líderes do Movimento, problemas estes que marcaram a história do Brasil nos últimos anos - um país que não conseguiu, desde sua fundação resolver ou minimizar o problema da propriedade da terra. Assim, nos pronunciamentos do senado e dos presidentes, nas entrevistas e artigos de jornais e revistas, todos vistos como artefatos culturais ${ }^{3}$ de análise, percorremos os principais debates legislativos e judiciários do período em questão, 1995 a 2006, que marcaram a temática político-juridica sobre o tema da reforma agrária no país, percebendo: a exclusão do povo da vida política, mediante sua ausência dentro do jogo discursivo, embora as construções discursivas sejam fundamentadas em seu nome, as diversas crises econômicas e financeiras, as lutas por democracia e justiça social, os acontecimentos trágicos e dramáticos das mortes no campo, o discurso das elites sobre o papel do Estado Contemporâneo, a criminalização judicial dos trabalhadores rurais sem terra, as críticas e as oposições ao governo de Fernando Henrique Cardoso (em seus dois mandatos) e de Luís Inácio Lula da Silva (no seu primeiro mandato), as intrigas político-partidárias dentro do Senado Federal e, sobremaneira, o foco central de nosso trabalho, a forma como todos os debates engendram o jogo político de aprovação de uma dada legislação, que fazem de uma lei o resultado dos embates e das lutas políticas em jogo em qualquer exercício do poder.

Analisando qual Reforma Agrária é o projeto considerado vencedor e quais os descaminhos percorridos insistentemente, constatamos como as leis são usadas no Brasil como instrumentos ambiguos, ora garantidores de direitos, ora como instrumentos cerceadores desses mesmos direitos, legitimando de forma ambigua o jogo politico instaurado. Sem necessitarmos de grandes esforços, e os debates do Parlamento nos informam visto que não é o objetivo acusar nenhum dos atores de 
JEANNE SILVA

mentirosos a menos que eles próprios o façam ${ }^{4}$ - das críticas, dos limites, das mazelas de corrupção de como se ordena e se desenvolve o jogo político de formulação e aplicação das leis. É esse desenrolar que fundamenta nosso trabalho, perseguindo a construção tensa de uma explicação científica que evidencie as tensões, os conflitos, os pactos, as fraturas expostas do jogo político exercido pelo três poderes (Executivo, Legislativo e Judiciário) da República Federativa do Brasil, com o incômodo histórico de compreender "para que servem as leis?"

Para a construção imagética de nosso pensamento elaboramos como arcabouço para esse entendimento a idéia do Labirinto. O labirinto é a imagem de um edifício compartimentalizado, com muitas divisões, muito corredores, e que nos remete à idéia de algo difícil, complexo, complicado de se encontrar uma saída. Assim sendo, o Labirinto é nossa metáfora. A Reforma Agrária é simbolicamente o tabuleiro desse jogo. Um jogo de sutilizas, onde a conceituação discursiva escorrega fluidamente de um momento a outro do jogo políticojurídico, um jogo prolongado no tempo e no espaço, que se arrasta indefinida e polifonicamente nas vozes de agentes sociais, atores políticos e operadores jurídicos presentes na vida brasileira, tanto do passado, quanto do presente, numa temática que, segundo expressão do senador Darcy Ribeiro, está "sempre inacabada, incompleta", numa linguagem que perpetua "as cercas" com que se bloqueiam as possibilidades de sua ocorrência, cercada não apenas com arames, fios e porteiras, mas também cercada pelas negações da própria linguagem, em mensagens implíticas ou não, como se de fato a temática Reforma Agrária exaustiva e constantemente re-elaborada, perdesse o sentido por uma hiperinflação de significados, como nos dizeres de Jean Baudrillard 5 .

Ao entrarmos nesse labirinto para compreensão da lei, cumpre-nos questionar sobre os caminhos e descaminhos da trajetória histórico-legislativa. A analisarmos os pronunciamentos dos senadores (pelo caminho do Legislativo), visualizamos sua interpretação contextual, seus projetos políticos, seus debates sobre lei, os conceitos e noções dos 
NOS LABIRINTOS DA LEI: A RETÓRICA DA REFORMA AGRÁRIA...

componentes de um Estado Democrático de Direito e algumas de suas regras de existência e fundamentação; e, concomitantemente a esses debates legislativos, o momento em que "projetos" viram lei, onde os projetos de fato já foram votados, se converteram em lei e se refletem na instância judiciária, sujeitos a apreciação dos juízes e desembargadores, numa frente de atuação diversa da anterior, agora comandada pelos agentes mais diversos do judiciário: advogados, promotores, juízes, desembargadores, ministros do Supremo Tribunal Federal, e outros.

A retórica é nossa chave metodológica de leitura, o fio interpretativo que nos permite caminhar pelo labirinto da reforma agrária, explicitando que os "conceitos são históricos" que "o direito pode ser uma retórica, mas não é necessariamente uma retórica vazia"7 , pois não existe retórica "vazia", pois todo argumento cumpre uma função. Assim, o conceito de Reforma Agrária é um conceito em fluxo constante, um campo para mudança e disputa, uma arena na qual interesses opostos apresentam reivindicações conflitantes. É por isso que nunca se lê um discurso qualquer de qualquer senador que seja contra a reforma agrária. Todos são a favor da reforma agrária. Resta-nos descobrir qual reforma agrária dentre as inúmeras propostas apresentadas. E são as leituras contínuas do parlamento que nos informam essas respostas para perceber os interesses em jogo no Brasil daquele momento e contexto histórico. O tema da reforma agrária, da propriedade privada, da defesa da lei e da ordem constituiu boa parte da retórica dos anos noventa, legitimando quase todo uso, prática ou direito reclamado, prosseguindo como uma demanda de pressão irresistível, acelerada em toda parte pelos meios de comunicação.

É possível verificarmos que no debate sobre a Reforma Agrária, o regime de defesa da propriedade privada também foi (e continua sendo) tão fervorosamente defendido quanto também criticado, e por mentes e por argumentos igualmente poderosos. Há discursos bem com há práticas, e o discurso deve, mais cedo ou mais tarde, fornecer à prática algum de seus contextos, o que é a razão pela qual os atores sociais ao lidarem 
constantemente com tais questões, debatiam e debatem o papel da opinião no governo e do Estado em tais questões. Privados de meios para articular uma consciência radical, os Movimentos Sociais se vêem obrigados a aceitar o discurso de seus governantes ou a formular fora dele modos de oposição semiótica e simbólica (daí o debate sobre até que ponto o crime seria e é uma forma de protesto social). Assim, figuras de destaque e as massas algumas vezes gritam juntas e, outras vezes, atiram-se umas contra as outras, e não temos por que considerar elite e cultura popular como duas coisas refratárias a uma interação e trânsito entre si $^{8}$.

Ao trabalharmos com o Movimento dos Trabalhadores Rurais Sem Terra, e analisá-los em seu confronto com os discursos oficiais contidos nos pronunciamento legislativos e processos criminais e cíveis, percebemos os diferentes significados que as leis, o direito, a função da propriedade privada e o próprio conceito de justiça vão assumindo na visão de agentes particulares, ou seja, percebendo como o conflito está latente em todos os setores materiais ou imateriais do mundo social, o que evidencia os múltiplos e conflituosos sentidos que a produção cultural assume na sociedade.

Uma sociedade não pode ser totalmente analisada sem que se inclua cada uma de suas práticas. Entretanto, não se pode separar essas práticas e submetê-las a leis distintas e especiais. Em outras palavras, não se atinge a totalidade pela soma das práticas. Não se podendo separar uma prática do conjunto anterior de outras. Não podemos isolá-la, nem relacioná-la de forma uniforme, estática e não histórica a alguma formação abstrata. Associamos a isso o fato de que, não se pode isolar o objeto e então descobrir seus componentes. Não se pode isolar a Ciência Jurídica e estudá-la como ciência "pura" (como é a proposta de Hans Kelsen ${ }^{9}$ ), isolada de seus componentes políticos, ideológicos, classistas, pois, ao fazermos isso esvaziamos sua dimensão social, valorativa, histórica.

Por outro lado, a idéia de que as leis são exclusivamente instrumentos da classe dominante não procede, é reducionista e nada explicativa. Para Thompson o direito define uma retórica: 
NOS LABIRINTOS DA LEI: A RETÓRICA DA REFORMA AGRÁRIA...

"define a imagem que certos elementos da classe dominante fazem de si mesmos, uma imagem profundamente interiorizada" 10 e assim o autor considera o direito como "mediação específica e um terreno de oposição de classes e não um simples instrumento ideológico a serviço da dominação da classe dominante"11. A pergunta crucial é como os sujeitos vivem essa realidade normativa? Como são forjados os inúmeros significados que a lei pode gerar? Como se acomodam e se toleram os conflitos dentro de uma ciência jurídica que tem como função precípua a tarefa de dirimir os conflitos sociais? Oliveira Viana ${ }^{12}$ assinala a idéia da qual compartilhamos como muito atual de que, historicamente, as elites têm outorgado paternalisticamente constituições e leis ao Brasil com pouca consideração ou consciência das expectativas e capacidades do povo governado. Em vez de ser o fruto de pressões populares, de um estudo fático sério, ou de uma cristalização dos costumes, a legislação é geralmente o produto daquilo que um pequeno grupo imagina ser "o bem do povo", ou também o que caracteriza como "o bem público com interesses particulares".

Insistindo na diferença entre os conceitos do que seja direito, lei e justiça, partimos da compreensão de que tais conceitos assumem definições variadas, ambíguas, flexíveis, dinâmicas. O "direito" é um regime de campo discursivo duplo: o das "leis" e o da "justiça". Tais categorias só adquirem significados quando encarnadas nos agentes sociais que as formulam, aplicam e interpretam as normas relativas à temática da Reforma Agrária. São categorias que se apresentam aos agentes sociais com graus diferenciados de percepção, carregando consigo parcelas de imponderabilidade e de incerteza. Assim, as leis não conseguem prever todas as possibilidades que os contextos histórico-sociais oferecem. Já discutimos em outro trabalho ${ }^{13}$ as premissas jurídicas que equiparam o direito ao sinônimo de lei, calcado no mito da racionalidade, da objetividade, da lógica, da unicidade, da imparcialidade, da impessoalidade. E agora nos apercebemos disso ao analisarmos o caminho histórico que percorre a 
legislação agrária em sua fixação de limites e elaboração de discursos exaltantes "da lei e da ordem".

Ao despirmos o campo conceitual do jurídico da roupagem positivista e supostamente neutra do qual é revestido, evidenciamos como os jogadores são adestrados para o "jogo" da retórica e da persuasão, deslocamos o embate para o campo do jogo, das malhas do processo judicial que permitem a construção de uma trama. Politizamos a discussão do campo jurídico reforçando que, compreender o jurídico, requer compreender o político, premissa chave para a compreensão da lei como ato humano histórico.

Por fim, partindo do entendimento de que as leis não se fazem e não adquirem significados exclusivamente no espaço legislativo (restrito ao Senado e Câmara dos Deputados), percebemos como o movimento social (integrantes, simpatizantes e/ou contrários) dos Trabalhadores Rurais Sem Terra, e vários outros agentes polifônicos, autoridades políticas, operadores jurídicos ou mídia, aderem ou não a esta causa social, problematizam e apresentam significações diferenciadas ou mesmo conflitantes para a noção do que seja o justo e o que seja legítimo no desempenho da função social da propriedade. Buscamos, assim, compreender as significações que são construídas, atribuídas ou forjadas no imaginário social, nas demarcações discursivas de vários componentes presentes no tema da reforma agrária: na defesa da propriedade privada, função social da propriedade, na criminalização do sem terra, nos projetos políticos propostos pelo Executivo, nas ações e julgamentos do judiciário.

Ao considerarmos que a lei também está presente na imaginação da sociedade que a cria, estamos afirmando que sua existência, finalidade, efeitos e conseqüências são construções sociais situadas no tempo e no espaço, onde os agentes sociais atuam in concreto. O direito faz parte do campo conceitual do imaginário social e a interpretação da lei seria impossível se os juristas e operadores do direito decidissem sair desse mesmo imaginário instaurado por eles. Assim, a atuação dos operadores jurídicos como mediadores entre a realidade social e a lei in 
NOS LABIRINTOS DA LEI: A RETÓRICA DA REFORMA AGRÁRIA...

abstrato fazem parte do imaginário social. Para Baczko, toda formulação de regras e normas legais do mundo do direito positivado (codificado) estão circunscritas a uma representação política que a sociedade formula para sua existência. Portanto, os discursos produzidos em "nome da lei" representam, no plano real, projetos políticos bastante precisos. O direito só existe enquanto prática encarnada nos homens, pois são estes mesmos homens que o constroem a partir de princípios e regras. Mas estas ações estão direta ou indiretamente vinculadas às representações que estes homens têm de si próprios, dentro do conjunto de suas crenças, mitos, ilusões, símbolos e valores. $O$ que é o direito senão esse conjunto de símbolos hierarquicamente dispostos que permitem a repressão e a aplicação de poderes de modo a dirimir e organizar a prática jurídica para a aplicação de uma dada lei e obtenção de uma suposta justiça? Assim sendo, existe uma constante luta política, social e econômica que dá-se no campo das representações, no qual os diversos segmentos sociais procuram impregnar o cenário jurídico de imagens que, via de regra, refletem os anseios de classes distintas, impondo ao imaginário social o controle e a difusão de símbolos e sinais como também os meios de assegurar o poder e sua perenidade histórica, "o domínio do imaginário e do simbólico é um importante lugar estratégico"14. O mapa dos projetos de reforma agrária são simbólicos, são imaginários. As elites políticas ao traçarem os rumos para o país o fazem com determinadas finalidades. Mas sabemos que os projetos e mapas não são garantidores, por si só, de que se alcance os objetivos e intenções programadas e planejadas.

Jacques Le Goff nos chamou a atenção para o fato de que a História das Mentalidades é uma história não de fenômenos "objetivos", porém da representação desses fenômenos e, nessa perspectiva, alimenta-se dos "documentos do imaginário" 15.

Não sendo a legislação um simples testemunho da sociedade, pode ser capaz de revelar os seus conflitos dissimulados e desejos realizados ou frustrados. Partindo, portanto, da referência discursiva, podemos concluir que uma 
JEANNE SILVA

das possibilidades do presente trabalho historiográfico é compreender, na articulação da linguagem jurídica os conflitos, os embates discursivos, os projetos coletivos realizados, os desejos consumados, as possibilidades implementadas, além do que alguns dos projetos, desejos e possibilidades frustradas. Naturalmente - na medida em que a produção judiciária não está fora de seu tempo, os desejos e disputas sociais estão de alguma forma, articulados com o movimento da sociedade à qual os agentes operadores do judiciário pertencem. É uma mediação complexa e que exige um cuidado particular para que não se caia na simplificação do "reflexo". Apesar desses riscos, o historiador não pode esquecer que o escritor é um homem do seu tempo ${ }^{16}$ e, como tal, também está influenciado pelas limitações da cultura de sua época. A começar pela própria linguagem - o código estabelecido -, mas também passando pelos temas, valores e normas, os legisladores (ao elaborarem as normas) e os operadores judiciais (ao fornecerem interpretação a tais normas) expressam os desejos, valores, projetos, conflitos, antagonismos e imaginários de uma dada sociedade materializada no tempo e no espaço.

Dessa forma, a linguagem política dos discursos políticos e judiciais exercem papel fundamental nas considerações aqui articuladas, pois, na análise das fontes legislativas e processuais evidenciamos que a linguagem não é transparente, linear, incisiva, impositiva. A linguagem flui também para as lacunas, as incertezas, as ambigüidades, a flexibilidade e a argumentação. Daí ser fundamental para nós a utilização das categorias "discurso" e "retórica".

Foucault pensa os discursos no interior de uma teoria crítica da sociedade. É precisamente a partir desta inclusão que se pode refletir sobre as condições de possibilidades dos discursos, ou seja, as condições que permitem que, em um dado momento histórico, as palavras tenham uma determinada significação e não outra. Como assinala Foucault, estas condições de possibilidade estão inscritas nos próprios discursos, forçando-os a enunciar certas coisas, indicando os objetos sobre os quais se pode falar. Foucault fala das formações 
NOS LABIRINTOS DA LEI: A RETÓRICA DA REFORMA AGRÁRIA...

discursivas, unidade teórica construída pela proposta de interdependência dos discursos e de suas condições de produção ${ }^{17}$.

O discurso constitui, dessa forma, um ato de argumentação, cujo principal problema teórico é configurado pela sua relação com os seus interlocutores. Nesta ótica, considera-se a retórica como uma investigação sobre os discursos, que objetiva dar conta do processo argumentativo na instância da própria prática lingüística. Segundo Warat: "a retórica, abrindo espaço para si nos estudos pragmáticos das linguagens e à sombra das análises oficiais, tenta romper com o tabu saussuriano e reivindica espaço para análises críticas"18.

Chaim Perelman contribui em nosso trabalho com sua análise para o entendimento da retórica jurídica ao analisar o "modus operandi" com que os argumentos são construídos por publicitários, políticos, juízes e filósofos em suas campanhas publicitárias, discursos, arrozoados, sentenças e tratados ${ }^{19}$, demonstrando diferenças entre convencer e persuadir, e evidenciando que a retórica resgata um raciocínio dialético de debate, de reflexão, e não de mera opinião. Desse modo, o pensamento retórico situa-se em um campo de observação que, mostrando certos efeitos do processo de persuasão, indica também os efeitos sociais de dominação. Em suma, o que Perelman expõe é que o pensamento é composto de uma parte lógica e uma parte dialética, sendo que a parte dialética foi negligenciada ao longo dos anos ${ }^{20}$ e precisamente essa idéia nos é cara como superação dessa negligência.

Empreendemos uma análise retórica dos discursos dos políticos, dos advogados, dos promotores, dos juízes, e mesmo das lideranças dos Movimentos Sociais que argumentam e constroem seus pensamentos e discursos; discursos estes que, formulando idéias, as materializam em suas ações políticas, administrativas e de julgamento de mundo. Discursos que, imbuídos de poder de convencimento e persuasão ${ }^{21}$ demonstram que os homens não são seres lógicos, mas seres de sugestão. Portanto, o lado emotivo, sugestivo, dos fenômenos é considerado essencial. Exemplos da propaganda, do discurso 
político, do discurso religioso, e mesmo o discurso jurídico, onde as argumentações da defesa ou acusação giram em torno da finalidade de "convencer e persuadir" o julgador; e mesmo dos debates dos senadores e deputados do legislativo, na qual a intenção é convencer e persuadir um determinado auditório, ainda que este auditório não seja os demais parlamentares, mas sejam indiretamente os eleitores que venham tomar contato com tais discursos taquigrafados através dos Anais do Congresso Nacional. Também não nos preocupamos com a verdade ou falsidades das afirmações, mas com as inúmeras possibilidades que as opiniões vão articulando até se cristalizarem em imposições. É neste terreno da transformação da opinião em verdade cristalizada e norma cogente que se nos introduz a noção de juízos de valor presentes nas normas e nas decisões político-juridicas, ocultadas dos olhos aparentemente leigos. Portanto, ancorados na retórica e no discurso discutiremos a adesão que se obtém através dos meios de argumentações discursivas. Para quem se preocupa, sobretudo com o resultado, persuadir é mais do que convencer: a persuasão acrescenta à convicção a força necessária que é a única que, segundo Perelman, conduziria à ação.

Assim, a retórica assume particular importância na análise dos discursos, pois, é o poder que as imagens e metáforas assumem no discurso, são as energias com que os sujeitos conseguem vincular a idéia à palavra e ao sentimento que conferem e nos remetem ao efeito de verdade, à formulação dos conceitos de verdade, política, justiça, que, em última instância, são todos construídos social e historicamente ${ }^{22}$. E geram energia, criam um efeito de verdade que fazem com que sua expressão persuasiva penetre nas almas e produza os sentimentos políticos $^{23}$, como afirma Pierre Ansart.

Em outros termos, a retórica é potente no tratamento discursivo dos temas e das tópicas advindas dos "regimes de verdade", da "justiça", da "lei", tornando-se a arte de argumentação privilegiada para a deliberação (dos rumos do país) e o julgamento (do judiciário em restrito) de questões as 
NOS LABIRINTOS DA LEI: A RETÓRICA DA REFORMA AGRÁRIA...

mais diversas possíveis, e no caso específico de nosso estudo, da Reforma Agrária.

Portanto, a Retórica está vinculada diretamente à forma como se constrói, se idealiza e de fato, se estabelece o funcionamento do mundo jurídico. A elaboração do conceito retórico do que é justo, do que seja justiça, é um elemento crucial para a teoria legal do direito, e tais implicações se encontram no campo do político. Num mundo onde as possibilidades da mentira são ilimitadas, a verdade e os fatos são inseguros, precários, a noção de justiça, também se vê constantemente ameaçada. Tanto a política, quanto o direito devem, com efeito, trilhar a estreita seara entre o perigo de tomar os eventos como resultados de algum desenvolvimento necessário que os homens não poderiam impedir e sobre os quais eles nada podem fazer, e o risco de negá-los, de tentar maquinar sua eliminação do mundo ${ }^{24}$.

Assim, numa análise retórica, há uma distinção entre os meios de convencer aos meios de persuadir, sendo os primeiros concebidos como racionais, os segundos como irracionais, dirigindo-se uns ao entendimento, os outros à vontade. Para quem se preocupa, sobretudo com o resultado, persuadir é mais que convencer: a persuasão acrescentaria à convicção a força necessária que é a única que conduzirá à ação. E é a persuasão que permite ao homem, com a utilização do poder das palavras, escolher entre uma série de possibilidades, as que melhor conduzem, ainda que de modo incerto, ao estabelecimento da paz. É dessa forma que a política é feita com palavras e atos que nos inserem no mundo humano. E essa inserção é como um segundo nascimento, no qual nos confirmamos e assumimos de forma original e singular, com liberdade pública para participação democrática. Sem "palavra" não somos livres, a liberdade exige o espaço público da palavra e da ação. É dessa forma que Hanna Arendt ${ }^{25}$ percebe o poder da palavra como processo gerador de poder, não só na dimensão da comunicação, mas na dimensão da revelação, onde ação, palavra e liberdade não são coisas dadas, mas requerem, para surgirem, a construção e manutenção do espaço público. 
JEANNE SILVA

Em meio às análises empreendidas, surgem outras discussões, secundárias e implícitas, mas não menos importantes: como o fracasso da idéia de racionalidade como a grande vencedora da modernidade e os exemplos das falhas e lacunas do modelo estatal empreendido. A racionalidade propugnada no mundo moderno não o salvou das catástrofes e incertezas da contemporaneidade e o direito moderno se transformou historicamente num direito estatal científico. E a crise da ciência (ou da infalibilidade da racionalidade científica) acarreta a crise do direito. "Crise" esta vista no âmbito de alguns autores, como a exemplo de Boaventura Souza Santos ${ }^{26}$, ou mesmo Castoriadis ${ }^{27}$, que usam o termo "crise" para avaliarem o conjunto de transformações pelos quais a sociedade dita "pós-moderna" atravessa. Daí inferir que o direito científico da modernidade não regula, nem emancipa as relações sociais entre os agentes que o operam e a sociedade a que se destina, fazendo surgir, nos dizeres de Claudine Haroche e Eugène Enriquez: "a face obscura das democracias modernas"28.

A expressão "crise" também pode ser usada quanto ao sistema representativo na organização dos partidos políticos que perderam sua centralidade como ordenadores estáveis das identidades e da preferência do eleitorado. Os partidos políticos representam quem? Não se pode pensar a política atual, analisar os discursos político-partidários sem uma discussão que permeie também o modelo dominante de representação que organiza as democracias contemporâneas, que segundo Lavalle e Houtzager, "entrelaçou o legislativo com lócus da representação" 29 e a relação daí derivada entre eleitor-eleito e da função de tais blocos organizativos. Essa relação fundamentada na expressão "governo representativo" estabelece definições claras quanto

a quem representa (o político), mediante que mecanismo é autorizado a representar e a que tipo de sanção ou controle estará submetido (as eleições), quem é representado (o eleitor), e de alguma forma, ainda que muito vaga, qual o conteúdo ou 
NOS LABIRINTOS DA LEI: A RETÓRICA DA REFORMA AGRÁRIA...

mandato a ser representado (programa ou promessas de campanhas $)^{30}$.

Aqui a crise consiste nas fraturas entre os interesses dos políticos, quer públicos, quer particulares e a relação deles com as expectativas e desejos dos governados. Entretanto, o voto e as eleições também apresentam sua faceta coercitiva (eleitores que são obrigados a comparecerem às urnas), elegendo representantes que, posteriormente terão liberdade ampla a decidirem, "falar por procuração", "falar em nome do povo", obrigando essa mesma população a acreditar na legitimidade dessa procuração, no poder deste mandatário e, a partir disso, respeitar as decisões vinculatórias que obrigam o povo à obediência política.

Todas as problemáticas enumeradas anteriormente apenas confirmam tendências que também interferem na Ciência jurídica, ciência esta que procura regular e normatizar a vida do cidadão (do eleitor) e do governante (eleito). Cria-se também novas demandas por direitos, por lutas democráticas e inserção de novos atores na cena política, que abre possibilidades de análises mais ricas e complexas no âmbito jurídico, principalmente no que tange à introdução das questões veiculadas às subjetividades e "sensibilidades jurídicas". O elemento da incerteza e a presença real do sujeito de direito propugnam por construções teóricas que primam por situarem os agentes em seu cotidiano, sem perderem de vista que os discursos por eles construídos são importantes manifestações de visões de mundo, exprimem as tensões sobre um modo de viver, construir seus valores e organizar suas instituições através das leis debatidas, aprovadas e julgadas. Possibilita compreendermos a lei em seu processo dinâmico de continuidade e de mudança, processo no qual é continuamente produzida e entendida enquanto emergente produto das relações sociais, ao invés de um aparato externo atuando sobre a vida social. Isto significa afirmar que a lei reflete a realidade e também é sua construtora. Sem esquecermos que a lei é uma forma de exercício do poder, mas lembrando o pressuposto de 
que não há uma relação de oposição entre pares, como poder e cultura/relações sociais. A Cultura incorpora e expressa a desigualdade, assim como as ideologias e relações de poder. Trata-se de um processo contínuo e complexo de produção de significados e sentidos - presentes em práticas e representações - compartilhados por determinados indivíduos de acordo com suas inserções sociais e específicas. Portanto, não basta apenas detalhar e compreender o discurso argumentativo e articulado da lei com a ameaça da força, mas há também a necessidade da busca de novas soluções frente ao processo de exclusão social que tem se operado dentro do mundo contemporâneo. Assim, a chamada "globalização" de mercados, instituições e culturas; também globaliza valores e conceitos (democracia, lei, justiça entre outros) - que aparecem como questões fundamentais de estudo, determinando a definição política de soberania nacional, de preservação de culturas locais, de construção de identidade e da busca de soluções para problemas dramáticos, como no exemplo da fome e do desemprego ${ }^{31}$, sentidos de forma mais perversa nos países periféricos, como é o caso do Brasil, onde o que aparece mais nitidamente é a face da in-justiça e da corrupção, e mesmo a discussão sobre o direito à resistência, em perceber as formas como os movimentos sociais podem enfrentar a dicotomia do que é legal versus o que é o legítimo.

$\mathrm{Na}$ construção deste campo analítico, a linguagem, a retórica e história estão entrelaçadas substancialmente. Aqui, História e linguagem se entrecruzam, numa zona que permitenos avaliar melhor as condições históricas de produção de nossas fontes judiciais. Trata-se, assim, como nos dizeres de G. Luz, de um

esforço de apontar direções para que se possa tratar a História como "discurso sobre discursos" sem, no entanto naturalizar o discurso em um lugar supostamente fora da temporalidade histórica ${ }^{32}$.

É dessa forma que entendemos a complexidade do discurso jurídico, sendo uma combinação de elementos retóricos, 
NOS LABIRINTOS DA LEI: A RETÓRICA DA REFORMA AGRÁRIA...

ideológicos, prescritivos, pedagógicos, coercitivos, mas que se encontram todos dentro de uma dada temporalidade histórica.

Dessa forma a retórica está presente historicamente nos pronunciamentos políticos, nos discursos dos presidentes, nos arrazoados e sentenças judiciais, nas táticas discursivas dos lideres dos movimentos sociais. $\mathrm{Na}$ análise de discursos judiciais, em particular, assume uma faceta de metadiscursividade, nunca sendo produtores originais de significados, mas abrindo-se a possibilidades de interpretações diversas, buscando os efeitos de sentidos para possíveis significados de defesa da propriedade privada, sendo esses efeitos de sentido históricos ${ }^{33}$.

A retórica difere da lógica, segundo Perelman, pelo fato de se ocupar não com a verdade abstrata, categórica, ou hipotética, mas com a adesão. Para que exista é preciso que o orador dê valor à adesão alheia e que aquele que fala tenha a atenção daqueles a quem se dirige: é preciso que aquele que desenvolve sua tese e aquele a quem quer conquistar formem uma comunidade, e isso pelo próprio fato do compromisso das mentes em interessar-se pelo mesmo problema. É o que acontece nos debates legislativos sobre os projetos a serem transformados em leis e posteriormente num outro momento nos escritos judiciais (processos e jurisprudências). Os debates legislativos e as peças processuais destinam-se a um auditório específico, particular, visam convencer os pares e organizar os grupos no interior das Assembléias Legislativas e, no Judiciário visa convencer os juízes, mas também se abrem a um auditório universal, visto, por exemplo, que a própria TV Senado ou TV Justiça permitem que pessoas assistam a tais oradores em determinadas circunstâncias. Essas circunstâncias também são peças fundamentais no entendimento do jogo retórico-político, pois o político usa de tais circunstâncias com finalidades específicas, seu discurso deve indicar os interesses que defende, mas, por outro lado, nem sempre essas intenções podem ou devem ser claras, diretas, daí aparecem as ambigüidades retóricas, exploradas o máximo possível. 
JEANNE SILVA

Na esfera judicial, onde há uma tríade composta pelo juiz, autor e réu, numa discussão, num confronto entre adversários ou parceiros que buscam convencer e persuadir um ao outro podem estes ver as opiniões de ambos modificadas em conseqüência da argumentação alheia. Chegam a um compromisso que será tão diferente da tese de um como da de outro, o que não pode acontecer se raciocinamos no interior de um sistema dedutivo univocamente fixado. É essa delicada noção de compromisso, que não é um contrato, mas uma modificação recíproca de juízos de valor que fazem com que, ao final do confronto ou da justaposição de argumentos, ambos saiam modificados. Quando não se ratifica esse compromisso e não se permite essa modificação de juízo, há a imposição da força, a imposição da vontade de um vencedor sobre um vencido, sendo que esta imposição pode se dar de diversas formas, desde a simples perda num processo de votação (no Legislativo) ou na perda de uma demanda jurisdicional frente a uma sentença judicial desfavorável. Resta-nos saber também até que ponto o convencimento argumentativo do outro, ou da parte adversa é transparente em suas intencionalidades, ou se também não enseja um jogo de cartas marcadas em uma sociedade dita "democrática", mas ao mesmo tempo marcada por profundas diferenças e exclusões, onde os diferentes segmentos sociais nem sempre estão abertos ao diálogo ou ao convencimento. Nesse momento, a força argumentativa e coercitiva do aparelho estatal se impõe, ou através da voz do juiz em sua sentença, ou da voz do Presidente da República em suas Medidas provisórias, ou aprovação de uma dada lei pela Instância Legislativa, num confronto de interesses de grupos diversos, que implica, inclusive, na luta pelo direito de dizer a "palavra", de tomar a "palavra", de impedir "a palavra".

Acrescente-se a isso a afetividade e os sentimentos políticos gerados pelos discursos políticos, que conforme Ansart marcam toda vida política da democracia atual. As disputas pelo poder exigem dos grupos um trabalho permanente para apoiar ou enfraquecer os sentimentos políticos, para mobilizá-los ou inibi-los ${ }^{34}$. 
NOS LABIRINTOS DA LEI: A RETÓRICA DA REFORMA AGRÁRIA...

$\mathrm{E}$ isto fica particularmente claro quando se vê constantemente as oposições, em todos os discursos políticopartidários acusando os adversários. No caso do presidente FHC, os discursos petistas acusam: "o presidente não está agindo", "o governo não faz nada", "falta vontade política". Expressões que se repetem constantemente. No caso posterior de Lula expressões do tipo "Lula não fez nada ainda", "a reforma agrária continua parada", "onde está o espírito combativo de Lula?"35

No caso dos Movimentos Sociais, a retórica cria por parte de suas lideranças a idéia da luta, da força do movimento, do descrédito do governo que ignora as aspirações do povo, e acima de tudo do sentimento de não desistência de se lutar e se obter a reforma agrária de aspiração popular, mesmo em meio a dores e sofrimentos, como no exemplo do lema: "ocupar, produzir, resistir".

Ao enfatizarmos a faceta argumentativa e retórica do direito $^{36}$ politizamos e historicizamos a ciência jurídica, percebendo o exercício jurídico como um exercício de interpretação construtiva. Portanto, não podem existir respostas "certas" a questões jurídicas polêmicas, mas apenas respostas "diferentes". Na maioria dos casos difíceis, existem respostas certas a ser procuradas pela razão e pela imaginação, o que evidencia o caráter inventivo dessa ciência e também os elementos ideológicos contidos em sua elaboração, pois, ao escolher uma resposta ao invés de outra, o agente, quer seja ele um juiz ou um legislador, demonstra quais os valores sociais que defende, realizando, portanto, a defesa do interesse de um grupo sobre outro. O direito é, sem dúvida, um fenômeno social, mas sua complexidade, função e conseqüências dependem de uma característica especial de sua estrutura. Ao contrário de muitos outros fenômenos sociais, a prática do direito é argumentativa ${ }^{37}$ e justamente nessa argumentação podemos perceber os interesses, os valores construídos pelas elites numa busca de determinar e fixar o que é dito como "certo" e como "errado", como "justo" e o "injusto", e separar o que é "legal" do que é "legítimo". Sendo que, no campo judicial tais decisões podem 
JEANNE SILVA

contribuir para construir ou abortar possibilidades de mudanças e atuação no social.

Portanto, as leis elaboradas (no campo legislativo) são discutidas no reino das possibilidades, com atuações dos agentes e atores históricos, com finalidades as mais diversas possíveis. Em seu processo de votação há conflitos, tensões, e no mais das vezes participação dos interesses dos grupos sociais que exercem pressão política sobre os parlamentares que a aprovam, sendo que inúmeras vezes a lei representa a derrota de um grupo e a vitória de outro, trazendo em si mesma as omissões, as lacunas, os imperativos do grupo vencedor que a aprova. A lei se apresenta, portanto, como uma relação direta de disputa de poder pelos grupos sociais nela envolvidos, um campo histórico tenso e de disputas pela demarcação de interesses. Depois de pronta a lei mostra ao povo apenas a sua faceta formal, estática, "harmônica", imperativa, coercitiva. É essa mesma lei que será analisada pelo Poder Judiciário, onde novamente será des-montada, questionada em sua lógica e burilada como matéria-prima pelos agentes operadores do direito. Assim sendo, tanto juízes, quanto legisladores (parlamentares) criam direito novo, a diferença entre eles é apenas de natureza formal, pois o legislador cria e inventa a partir de direito legislado e o juiz cria a partir de direito julgado. Entretanto, ambos não se encontram livres e isolados das forças políticas, sociais e históricas do tempo em que vivem. $\mathrm{E}$ em matéria de reforma agrária cada vez que o judiciário, através do aparato legal da manutenção de privilégios se compactua com o legislativo (onde interesses particulares se sobrepõem a interesses públicos gerais) e com o executivo que se omite da realização de políticas públicas coerentes e operacionalizáveis, o "Estado Democrático" sai empobrecido e o povo perde, de fato, a oportunidade de experimentar algo que ainda não conhecemos em sua plenitude, pois, ainda não conseguimos inventar: uma democracia, onde de fato os poderes sejam harmônicos, onde de fato impere justiça social. De fato constatamos que, ainda não saímos do preâmbulo da Constituição (e o preâmbulo 
NOS LABIRINTOS DA LEI: A RETÓRICA DA REFORMA AGRÁRIA...

constitucional é um texto sem normas, pois seu argumento fático se encontra no político e não no jurídico) que argumenta:

o estado democrático de direito é destinado a assegurar o exercício dos direitos sociais e individuais, a liberdade, a segurança, o bem estar, o desenvolvimento, a igualdade e a justiça como valores supremos de uma sociedade fraterna, pluralista e sem preconceitos, fundada na harmonia social e comprometida, na ordem interna e internacional, com a solução pacífica das controvérsias ${ }^{38}$. verbo...

Ainda não chegamos ao começo! $\mathrm{E}$ no princípio era o

\section{Referências Bibliográficas}

ARENDT, Hannah. "O conceito de História - antigo e moderno" e "Verdade e História", in Entre o passado e o futuro [1961], São Paulo, Ed. Perspectiva, 1992, 3. ${ }^{a}$ ed., pp. 69-126; 282-325.

. Origens do Totalitarismo. Trad. Roberto Raposo. São Paulo. Cia das Letras. 1989.

. O que é Política? 2a ed., Rio de Janeiro: Bertrand Brasil, 1999.

ANSART, Pierre. "Mal-estar ou fim dos amores políticos", Revista História \&Perspectivas, 2002.

BACZKO, Bronislaw. In: "Imaginação Social". Enciclopédia Einaud - vol. 5 anthropos-homem. 288. Lisboa. Imprensa Nacional Casa da Moeda.

BAUDRILLARD, Jean. "À sombra das maiorias silenciosas - o fim do social e o surgimento das massas". Trad. Suely Bastos. 2. ${ }^{\text {a }}$ ed. Editora Brasiliense. 1985

BAUMAN, Zygmunt. Modernidade e Ambivalência. In: Mike Featherstone. Cultura Global: Nacionalistmo, Globalização e Modernidade. Petrópolis: Vozes, 1994.

. Comunidade: A busca por segurança no mundo atual. Trad. Plínio Dentzien. Rio de Janeiro: Jorge Zahar ed.; 2003.

. Em busca da política. Rio de Janeiro: Zahar, 2000.

BLOCH, Marc. L. B. Apologia da história ou, O ofício do historiador. Prefácio de Jacques Le Goff, apresentação à ed. brasileira de Lilia Moritz Schwarcz. Trad. André Telles. Rio de Janeiro. Ed. Zahar, 2001. 
JEANNE SILVA

BRESCIANI, Maria Stella Martins. O charme da ciência e a sedução da objetividade: Oliveira Viana interpreta o Brasil. Tese titular apresentada ao Departamento de História/UNICAMP, 2002.

CASTORIADIS, Cornelius. "A ascensão da insignificância", In: As encruzilhadas do labirinto - vol. 04. São Paulo: Paz e Terra, 2002.

DWORKIN, R. "As Leis". In: O Império do Direito. Trad. Jefferson Luiz Camargo. São Paulo: Martins Fontes, 2003

FOUCAULT, Michel. "A ordem do discurso". Aula inaugural no Collège de France, pronunciada em 02/12/1970. Trad. Laura Fraga de Almeida Sampaio. 3. ${ }^{\mathrm{a}}$ ed. Loyola, São Paulo, 1996.

. "A verdade e as formas jurídicas". Cadernos da PUC do Rio de Janeiro, departamento de Letras, Trad. Roberto Cabral de Melo Machado. 1979

GINZBURG, Carlo. "Apontar e Citar. A verdade da história" [1989], In: Revista de história, IFCH, UNICAMP, 1991.

Anya, 1993.

"El Juez e el historiador". Tradução Alberto Clavería, Madrid, GRAU, Eros Roberto. O direito posto e o direito pressuposto. Malheiros ed. $4 .^{\text {a }}$ ed. 2002.

HAROCHE, Claudine. Reserva nos costumes e controle da violência política: a tese de Norbert Elias. In: Da palavra ao gesto, Campinas, 1998.

. Da palavra ao gesto. Campinas - SP: Papirus, 1988.

. "Fazer dizer, querer dizer'. Trad. Eni Pucinelli Orlandi. Editora Hucitec, São Paulo, 1992.

HAROCHE,C. \& ENRIQUEZ, E. La face obscure des démocraties modernes. Sociologie clinique. Éditions Éres. 2002

LE GOFF, Jacques. "As mentalidades, uma história ambígua". In: História: novos objetos. Trad. de Terezinha Marinho. Rio de Janeiro, Francisco Alves, 1976

LAFER,C. Hanna Arendt: Pensamento, Persuasão e Poder. 2. ${ }^{a}$ Ed., São Paulo, Paz e Terra, 2003.

LAVALLE, A.G., HOUTZAGER,P.P.,CASTELLO,G. "Democracia, Pluralização da representação e da sociedade civil". Revista Lua Nova. São Paulo, 67:49-103, 2006.

LECHNER, Norber. Os novos perfis da política: um esboço. Revista Lua Nova. N 67, São Paulo, 2006.

LOPREATO, C., MAGALHÃES,M.B. (orgs). "A banalização da violência: atualidade do pensamento de Hanna Arendt". Rio de Janeiro: Relume Dumará, 2004. 
NOS LABIRINTOS DA LEI: A RETÓRICA DA REFORMA AGRÁRIA...

LYRA FILHO, Roberto. O que é direito. São Paulo: Brasiliense. Coleção Primeiros Passos. 8. ${ }^{a}$ reimpr. da 17 ed. 2003.

PERELMAN, Chaim. Tratado da argumentação. Prefácio de Fábio Ulhôa Coelho: Tradução Maria Ermantina Galvão. São Paulo: Martins Fontes, 1996.

. Retóricas. Trad. Maria Ermantina Galvão. São Paulo: Martins Fontes, 1997.

POCOCK, J.G. Introdução: O Estado da Arte e O conceito de linguagem e o métier d historien. In: Linguagens do Ideário político. Sérgio Miceli [org]. Trad. Fábio Fernandes- São Paulo: Editora da Universidade de São Paulo. 2003.]

RICOEUR. P. O justo ou a essência da justiça. Edição Odile Jacob, Instituto Piaget. Outubro de 1995. p.10.

SANTOS, Boaventura de Sousa. "A crítica da razão indolente contra o desperdício da experiência, para um novo senso comum: a ciência, o direito e a política na transição paradigmática", 3. Ed. São Paulo: Cortez, 2001.

- "Pela mão de Alice. O social e o político na pós-modernidade. 8. ${ }^{\mathrm{a} e d}$. São Paulo: Cortez, 2001.

SILVA. J. Sob o jugo/jogo da Lei. Confronto histórico entre direito e justiça. Edufu - Editora da Universidade Federal de Uberlândia. 2006 THOMPSON, E. P. Senhores e Caçadores - Trad. Denise Bootmann. Rio de Janeiro, Paz e Terra, 1987.

- Costumes em Comum: Estudos sobre a Cultura Popular Tradicional. São Paulo: Cia das Letras, 1988.

. A formação da classe operária inglesa. Tradução Denise Bottman. Rio de Janeiro, Paz e Terra, vol. I, II e III, 1987.

VIANA, Oliveira. Instituições Políticas Brasileiras [1949]. Belo Horizonte: Editora Itatiaia, 1987. Volumes I e II.

WARAT, Luís Alberto. A ciência jurídica e seus dois maridos. Santa Cruz do Sul, Faculdades Integradas de S. C. do Sul, 1985.

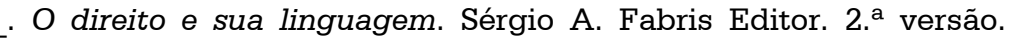
Porto Alegre. 1995.

SILVA, Jeanne. In the Labyrinths of the Law: the rhetoric of Agrarian Reform in the Democratic State - Brazil 1995/2006. História, v.28, n.2, p.467-494, 2009. 
JEANNE SILVA

\begin{abstract}
This article has objective to present in condensed form, part of the reflections of the author's search. Discusses some links between law and history. Search historical evidence as the law is an argumentative practice, as are built and designed the arguments that allowing an group political outlining the direction for the country by creating a law that criminalizes the actions of various social movements, specifically the MST- Movimento dos Trabalhadores Rurais Landless, making the problem "political" of agrarian reform in legal case the "police."
\end{abstract}

Keywords: Law; Political history; Agrarian reform.

\title{
NOTAS
}

${ }^{1}$ Este artigo é parte integrante da Tese de doutoramento desenvolvida pela acadêmica, com o mesmo título, junto ao Instituto de História da Universidade Federal de Uberlândia, na linha de pesquisa Política e Imaginário, adaptado para formato de artigo a ser apresentado na Revista História.

${ }^{2}$ SILVA, J. Sob o jugo/jogo da lei: confronto histórico entre direito e justiça. EDUFU- Editora da Universidade Federal de Uberlândia,2006.

${ }^{3}$ POCOCK, J.G. Introdução: O Estado da Arte e $\mathrm{O}$ conceito de linguagem e o métier d`historien. In: Linguagens do Ideário político. Sérgio Miceli [org]. Trad. Fábio Fernandes- São Paulo: Editora da Universidade de São Paulo. 2003

${ }^{4}$ Idem.

${ }^{5}$ BAUDRILLARD, Jean. "À sombra das maiorias silenciosas - o fim do social e o surgimento das massas". Trad. Suely Bastos. 2. ${ }^{a}$ ed. Editora Brasiliense. 1985

${ }^{6}$ THOMPSON, E. P. Senhores e Caçadores - Trad. Denise Bootmann. Rio de Janeiro, Paz e Terra, 1987.

${ }^{7}$ THOMPSON, E. P. Costumes em Comum: Estudos sobre a Cultura Popular Tradicional. São Paulo: Cia das Letras, 1988. p. 22.

${ }^{8}$ POCOCK, J.G. Introdução: O Estado da Arte e $\mathrm{O}$ conceito de linguagem e o métier d historien. In: Linguagens do Ideário político. Sérgio Miceli [org]. Trad. Fábio Fernandes- São Paulo: Editora da Universidade de São Paulo. 2003

${ }^{9}$ KELSEN. H. Teoria Pura do Direito. Ed. Martins Fontes. 2006 
NOS LABIRINTOS DA LEI: A RETÓRICA DA REFORMA AGRÁRIA...

${ }^{10}$ THOMPSON, E. P. Peculiaridades dos Ingleses e outros artigos. [org.] Antonio Luigi Negro e Sergio Silva. Campinas, São Paulo, Editora da Unicamp, 2001. p. 209 e 211.

${ }^{11}$ Idem.

${ }^{12}$ VIANA Oliveira. Instituições Políticas brasileiras [1949]. Belo Horizonte: Editora Itatiaia, 1987. Vol. II, p.30,149

${ }^{13}$ SILVA. J. Sob o jugo/jogo da Lei. Confronto histórico entre direito e justiça. Edufu - Editora da Universidade Federal de Uberlândia. 2006

${ }^{14}$ BACZKO, Bronislaw. In: Imaginação Social. Enciclopédia Einaud - vol. 5 anthropos-home. 288. Imprensa Nacional - Casa da Moeda. p 297.

${ }^{15} \mathrm{LE}$ GOFF, Jacques. "As mentalidades, uma história ambígua". In: História: novos objetos. Trad. de Terezinha Marinho. Rio de Janeiro, Francisco Alves, 1976.

${ }^{16}$ BLOCH, Marc. Apologia da História ou Ofício do historiador. Prefácio de Jacques Le Goff. Ed. Brasileira Lilia M. Schwarcz. Trad. André Telles. Rio de Janeiro: Jorge Zahar. Ed. 2004.

${ }^{17}$ Mais especificamente "A verdade e as formas jurídicas" e " A ordem do Discurso" que trabalham a questão do discurso jurídico e as condições de sua enunciabilidade, que marcam a influência que a análise do discurso exerceu na elaboração deste trabalho.

${ }^{18}$ WARAT, Luis Alberto. "O direito e sua linguagem". In: discurso jurídico e retórica. 2. ${ }^{a}$ ed. Revista. Sergio Antonio Fabris Editor. Porto Alegre. 1995.

${ }^{19}$ PERELMAN, Chaim. Tratado da argumentação. Prefácio de Fábio Ulhôa Coelho: Tradução Maria Ermantina Galvão. São Paulo: Martins Fontes, 1996. p 11

${ }^{20}$ PERELMAN, CHAIM. Retóricas. In: Lógica e Retórica. Trad. Maria Ermantina Galvão. São Paulo: Martins Fontes, 1997

${ }^{21}$ PERELMAN, CHAIM. Retóricas. In: Lógica e Retórica. Trad. Maria Ermantina Galvão. São Paulo: Martins Fontes, 1997. p. 58.

${ }^{22}$ FOUCAULT, Michel. "A ordem do discurso". Aula inaugural no Collège deFrance, pronunciada em 02/12/1970. Trad. Laura Fraga de Almeida Sampaio.3. ${ }^{a}$ ed. Loyola, São Paulo, 1996.p 10.

${ }^{23}$ BRESCIANI, Maria Stella Martins. O charme da ciência e a sedução da objetividade: Oliveira Viana entre intérpretes do Brasil. São Paulo: UNESP, 2005

${ }^{24}$ ARENDT, Hannah . "Verdade e História", in: Entre o passado e o futuro [1961], São Paulo, Ed. Perspectiva, 3.ed.,1992. 
JEANNE SILVA

${ }^{25}$ LAFER. C. Hanna Arendt: Pensamento, persuasão e poder. Ed. Paz e Terra, 2. ${ }^{\text {a }}$ Ed. 2003.

${ }^{26}$ SANTOS, Boaventura de Sousa. "A crítica da razão indolente contra o desperdício da experiência, para um novo senso comum: a ciência, o direito e a política na transição paradigmática", 3. Ed. São Paulo: Cortez, 2001.

${ }^{27}$ CASTORIADIS, Cornelius. "A ascensão da insignificância", In: As encruzilhadas do labirinto - vol. 04. São Paulo: Paz e Terra, 2002.

${ }^{28} \mathrm{HAROCHE}, \mathrm{C}$. \& ENRIQUEZ, E. La face obscure des démocraties modernes. Sociologie clinique. Éditions Éres. 2002.

${ }^{29}$ LAVALLE, A.G., HOUTZAGER,P.P.,CASTELLO,G. "Democracia, Pluralização da representação e da sociedade civil". Revista Lua Nova. São Paulo, 67:49-103, 2006.

${ }^{30}$ LAVALLE, A.G., HOUTZAGER,P.P.,CASTELLO,G. "Democracia, Pluralização da representação e da sociedade civil". Revista Lua Nova. São Paulo, 67:49-103, 2006.

${ }^{31}$ BAUMAN , ZYGMUNT. Comunidade: A busca por segurança no mundo atual. Trad. Plínio Dentzien. Rio de Janeiro: Jorge Zahar ed.; 2003.

${ }^{32}$ LUZ, G.A. "A insubordinação da história à retórica: manifesto transdisciplinar. Revista ARTCULTURA, do Instituto de História da Universidade Federal de Uberlândia. n.09, Uberlândia, Semestral jul-dez, 2004. p.107.

${ }^{33}$ LUZ, G. A. "A insubordinação da história à retórica: manifesto transdisciplinar. Revista ARTCULTURA, do Instituto de História da Universidade Federal de Uberlândia. n.09, Uberlândia, Semestral jul-dez, 2004. p.109

${ }^{34}$ ANSART. P. "Mal estar ou fim dos amores políticos?". Trad. Jacy Alves Seixas. Revista História \& Perspectivas, Uberlândia, (25-26): 55-80, Jul/Dez. 2001/Jan/Jul.2002. p. 60

${ }^{35}$ Expressões constantemente empregadas na parte dos pronunciamentos dos senadores, analisados em seu conjunto. Anais do Senado Federal. Site de consulta: http://www.senado.gov.br, período consultado 1995 em diante.

${ }^{36}$ DWORKIN, R. "As Leis". In: O Império do Direito. Trad. Jefferson Luiz Camargo. São Paulo: Martins Fontes, 2003. p 17

${ }^{37}$ DWORKIN, R. "As Leis". In: O Império do Direito. Trad. J. L.Camargo. São Paulo: Martins.2003.

${ }^{38}$ BRASIL. Constituição Federal da República Federativa do Brasil de 1988, preâmbulo. Publicada no Diário Oficial da União $\mathrm{n}^{\circ} 191-\mathrm{A}$, de 05 de Outubro de 1988.

Artigo recebido em 06/2009. Aprovado em 11/2009. 